\title{
URINARY TRACT INFECTION \\ IN HIGH RISK PREGNANT WOMEN
}

Erica Freire de Vasconcelos-Pereira, Ernesto Antonio Figueiró-Filho, Vanessa Marcon de Oliveira, Ana Cláudia Oliveira Fernandes, Clícia Santos de Moura Fé, Lílian Rezende Coelho and Ili Breda ${ }^{1}$

\begin{abstract}
Background: In this study, we aimed to verify the frequency of urinary tract infection (UTI) in pregnant women, the main etiologic agents and their antibiotic susceptibilities. Moreover, to confirm UTI as a risk factor for maternal and fetal complications. Methodology: Data collection was performed using medical records from pregnant women suffering from UTIs (the Study Group) and pregnant women without UTIs (the Control Group). Both groups of patients visited the Department of High Risk Pregnancy, University Hospital, Federal University of Mato Grosso do Sul during the period of April 2005 to April 2010. Results: Of the 864 pregnant women studied, 15.6\% (135/864) had a UTI. Escherichia coli was the most frequent cause of urinary tract infections, with a frequency of $34.8 \%(47 / 135)$. The E. coli strains were most sensitive to norfloxacin $(91.4 \%)$, nitrofurantoin $(80.8 \%)$ and ceftriaxone $(74.4 \%)$ and most resistant to ampicillin (42.5\%), trimethoprim-sulfamethoxazole (31.1\%) and first-generation cephalosporins (14.8\%). There was a significant association between preterm delivery, low birth weight and UTI in pregnant women. There was no significant association with premature rupture of membranes, admission to Neonatal Intensive Care Unit (Neo ICU) and Apgar of less than 7 at $5 \mathrm{~min}$. Conclusion: The use of urine culture as routine prenatal laboratorial screening allows for the early diagnosis and treatment of UTIs in pregnant women, thereby providing better perinatal conditions.
\end{abstract}

KEY WORDS: Urinary tract infection; pregnancy complications; prenatal.

\section{RESUMO}

Infecção do trato urinário em gestantes de alto risco

Objetivo: Verificar a freqüência de infecções do trato urinário, seus principais agentes etiológicos e suscetibilidade aos antimicrobianos em gestantes. Além disso, verificar a ITU como fator de risco para

1 Faculty of Medicine, Federal University of Mato Grosso do Sul (UFMS), Campo Grande (MS), Brazil.

Corresponding author: Ernesto Antonio Figueiró-Filho. Núcleo do Hospital Universitário - Divisão de Apoio Acadêmico e Cientifíco - NHU/DIAC. Rua Senador Filinto Muller, 335 - Cidade Universitária - Vila Ipiranga. Zip Code: 79080-190. e-mail: eafigueiro@uol.com.br. Campo Grande (MS), Brazil.

Received for publication in: 14/6/2011. Reviewed in: 11/4/2012. Accepted in: 15/1/2013. 
complicações materno-fetais. Metodologia: Coletamos dados de prontuários de gestantes do grupo de estudo com infecção urinária e grupo de comparação sem infecção do trato urinário, do Serviço de Gravidez de Alto Risco do Hospital Universitário da Universidade Federal de Mato Grosso do Sul durante o período Abril de 2005 a Abril de 2010. Resultados: Das 864 gestantes estudadas, 15,6\% (135/864) apresentaram infecção do trato urinário. Escherichia coli foi a bactéria mais freqüente em $34,8 \%(47 / 135)$ dos casos. Cepas de E. coli foram mais sensíveis à norfloxacina $(91,4 \%)$, nitrofurantoína $(80,8 \%)$ e ceftriaxona $(74,4 \%)$ e mais resistentes à ampicilina $(42,5 \%)$, sulfametoxazol-trimetoprima $(31,1 \%)$ e cefalosporinas de primeira geração $(14,8 \%)$. Houve associação significativa entre parto pré-termo, baixo peso ao nascer e infecção do trato urinário. Não houve associação significativa com ruptura prematura de membranas, admissão em UTIneo e Apgar menor que 7 em 5 min. Conclusão: O uso de urocultura como triagem pré-natal de rotina permite diagnóstico precoce e tratamento da infecção urinária em mulheres grávidas, permitindo melhores condições perinatais.

DESCRITORES: Infecção urinária; complicações na gravidez; pré-natal.

\section{INTRODUCTION}

Urinary tract infections (UTIs) are one of the most common disorders, and are extremely detrimental during pregnancy due to the possibility of maternal-fetal complications, including septicemia, intra-amniotic infection, preterm labour, premature rupture of membranes, low birth weight, intrauterine growth restriction (IUGR) and perinatal death $(2,7,25,26,29,31)$.

The high incidence of UTIs during pregnancy is related to the abnormal anatomical-physiological changes that occur during this period, such as compression of the ureter by uterine dextrorotation, higher prevalence of vesicoureteral reflux, hydroureter and the alkalinization of the vaginal $\mathrm{pH}$. All of these conditions may predispose the patient to develop from an asymptomatic UTI into a symptomatic infection $(7,25,27,30)$.

Asymptomatic bacteriuria affects 5-12\% of pregnant women, with $30 \%$ developing cystitis and another $50 \%$ progressing to pyelonephritis $(25,32)$. Screening for asymptomatic bacteriuria should be performed during the prenatal period by urine culture. When diagnosed, the immediate assessment of requirement for treatment is essential as there is evidence supporting a link to the development of pyelonephritis and possible obstetric complications $(11,26,29,30)$. Maternal complications of UTIs occur more frequently in cases of pyelonephritis, including $1-2 \%$ of pregnant women, due to tissue damage caused by the bacterial endotoxin $(7,14)$.

The microbiological profile of genitourinary infections includes Escherichia coli as the most frequently associated pathogen (10, 18, 23, 25). Understanding of the epidemiology and susceptibility pattern to antimicrobial agents is essential, thereby reducing the possibility of the failure of treatment and favoring the conditions required to offer the best therapeutic choice $(5,23)$.

The aim of this study was to verify the frequency of UTIs, the most prevalent etiologic agents and their antimicrobial susceptibilities of in pregnant women treated as outpatients. Moreover, to verify UTI as a risk factor for maternal and fetal complications. 


\section{MATERIALS AND METHODS}

This study was an observational and retrospective study that included a comparison group and was conducted from April 2005 to April 2010 at the Clinic for High Risk Pregnancy, University Hospital (UH) College of Medicine, Federal University of Mato Grosso do Sul (FAMED-UFMS). All pregnant women with UTIs confirmed by positive urine culture results were analyzed during this period and included in the Study Group (SG). The same number of pregnant women without a urinary tract infection was included in the Control Group (CG).

We surveyed 864 medical records from pregnant women attending the Clinic for High Risk Pregnancies. Of these patients, 135 had a UTI (Study Group - SG), and 135 women without a UTI were included for comparison (Control Group - CG). Patients without a UTI were selected randomly from among the surveyed sample.

Inclusion criteria for the Study Group: Regular prenatal care at the Clinic for High Risk Pregnancy, University Hospital (UH) School of Medicine, Federal University of Mato Grosso do Sul (UFMS-FAMED); delivery in the maternity unit of the same establishment; age greater than 18 years, or, if lower, show authorization of the legal guardian; consent to participate in the study and a signed the consent form (CF). We use indigenous origin as a criterion for exclusion from the SG.

Inclusion criteria for the Control Group: present a negative urine culture throughout pregnancy; have records at the Clinic of High Risk Pregnancy, University Hospital (UH) School of Medicine, Federal University of Mato Grosso do Sul (UFMS-FAMED); delivery in the maternity unit of the same establishment. We used as exclusion criteria: description of some UTI during pregnancy in the medical record; being of indigenous origin.

All pregnant women in the SG were informed about the objectives and methodology of the study, and admitted after signing a consent form. Only data from medical records were used for the patients in the comparison group, no fresh contact was made with the mothers in this group.

With the collected data, we compared the SG and CG, assessing the rate of perinatal complications such as low birth weight, premature rupture of membranes, preterm delivery, admission of newborns in the Neonatal Intensive Care Unit (Neo ICU) and Apgar of less than 7 at 5 minutes.

The association between nonparametric variables was evaluated by Chi-squared and two-tailed Fisher exact tests on contingency tables of double entry, with the expression of " $p$ " and an odds ratio (OR) with a confidence interval of $95 \%$ (CI95\%). Associations were considered to be significant when $\mathrm{p}<0.05$.

This study was approved by the Ethics Committee in Human Research (ECHR) of Universidade Federal de Mato Grosso do Sul, Protocol No. 860 of 08/03/2007. 


\section{RESULTS}

The average age of patients in the SG was $26.9 \pm 6.5$ years ( 18 to 46 years), and $26.9 \pm 6.7$ years ( 18 to 44 years) in the CG. There was no significant difference $(p=0.95)$ between the average ages of patients in both groups. With respect to parity, we observed that among the infected patients, $32.5 \%$ were primiparous, whereas in the comparison group, $35.5 \%$ had four or more pregnancies, demonstrating a statistically significant difference $(\mathrm{p}<0.001)$.

The frequency of UTI was $15.6 \%$ (135/864). Among these patients, $7.5 \%(65 / 864)$ had cystitis and urethritis, 5.2\% (45/864) presented asymptomatic bacteriuria, and $1.2 \%(10 / 864)$ presented pyelonephritis. Among the microorganisms isolated from the urine tests, Escherichia coli $(34.8 \%)$ was the most common bacteria, followed by Klebsiella pneumoniae (11.8\%) and Enterobacter sp. (6.6\%). Streptococcus agalactiae was present in 5.19\% (7/135) of the urine cultures. The E. coli strains were more sensitive to norfloxacin (91.4\%), nitrofurantoin $(80.8 \%)$ and ceftriaxone (74.4\%). There were high rates of resistance to ampicillin $(42.5 \%)$, trimethoprim-sulfamethoxazole (31.1\%) and first-generation cephalosporins (14.8\%).

Outpatient treatment was performed in 78.5\% (106/135) of the cases of pregnant women with UTIs, with the drug chosen according to the urine culture, the dosage and duration as recommended in the literature. Hospital admission was required in $13.3 \%(16 / 135)$ of the patients. Nothing related to treatment was described in the records of $9.6 \%(13 / 135)$ of patients in the SG. The most widely used drugs as outpatients were nitrofurantoin (40.7\%), cephalexin (11.8\%) and norfloxacin (74\%), which were used orally for 10 days, as guided by urine culture. A urine sample after treatment, although requested of all the pregnant women with treatment described in the records, was performed in only $68.8 \%(93 / 135)$ of the patients.

The patients in the SG and the CG did not show premature membrane rupture in most of the samples analyzed, and this association was not significant, as shown in Table 1. There was no statistically significant association between a UTI and an Apgar score below 7 at 5 minutes (Table 2) or admission of newborn infants to Neo ICU (Table 2).

In addition, the SG had UTI rates that were 2.2 times higher for infants with a gestational age less than 37 weeks, with a statistically significant association $(\mathrm{p}=0.03, \mathrm{OR}=2.43, \mathrm{CI} 95 \%=1.4$ to 5.78$)$, as shown Table 1 . Also in agreement with previous results, newborns with low birth weight were present at higher percentages in the women with UTIs $(21.5 \%)$ when compared to the CG $(5.9 \%)$. This association was significant $(\mathrm{p}=0.009, \mathrm{OR}=4.0 \mathrm{C} 195 \%=1.66$ to 9.98$)$, as shown in Table 2. Although the rates of cesarean delivery are high in both groups (Study and Control), being high-risk pregnancies for patients services, the group with UTI had approximately twice (1.86) the number of vaginal deliveries as the CG. This association was significant $(\mathrm{p}=0.001, \mathrm{OR}=0.41 \mathrm{CI} 95 \%=0.23$ to 0.73 ), Table 1 . We suggest that the higher rate of vaginal delivery in the Study Group results from greater association with the work of preterm delivery. 
Table 1. Association of urinary tract infection, premature rupture of membranes, type of delivery and preterm delivery in pregnant women with and without urinary tract infections.

\begin{tabular}{|c|c|c|c|c|c|}
\hline & \multicolumn{2}{|c|}{ Urinary Tract Infection } & & \multirow[t]{2}{*}{$p$} & \multirow[t]{2}{*}{$\begin{array}{c}\text { OR (IC95\%) } \\
\text { (IC 95\%) }\end{array}$} \\
\hline & Present & Absent & & & \\
\hline Premature rupture of membranes & $\mathrm{N}(\%)$ & $\mathrm{N}(\%)$ & & & \\
\hline Yes & $9(6.7 \%)$ & $5(3.7 \%)$ & $14(5.2 \%)$ & \multirow{3}{*}{$* 0.41$} & \multirow{3}{*}{$\begin{array}{c}1.86 \\
(0.55-6.57)\end{array}$} \\
\hline \multirow[t]{2}{*}{ No } & $126(93.3 \%)$ & $130(96.3 \%)$ & $254(94.8 \%)$ & & \\
\hline & $135(100 \%)$ & $135(100 \%)$ & $270(100 \%)$ & & \\
\hline \multicolumn{6}{|l|}{ Type of delivery } \\
\hline Cesarean & $81(60 \%)$ & $106(78.5 \%)$ & $187(69.3 \%)$ & \multirow{3}{*}{$* 0.001$} & \multirow{3}{*}{$\begin{array}{c}0.41 \\
(0.23-0.73)\end{array}$} \\
\hline \multirow[t]{2}{*}{ Vaginal } & $54(40 \%)$ & $29(21.5 \%)$ & $83(30.7 \%)$ & & \\
\hline & $135(100 \%)$ & $135(100 \%)$ & $270(100 \%)$ & & \\
\hline \multicolumn{6}{|l|}{ Preterm Delivery } \\
\hline Yes & $22(16.3 \%)$ & $10(7.4 \%)$ & $32(11.9 \%)$ & \multirow{3}{*}{$* 0.03$} & \multirow{3}{*}{$\begin{array}{c}2.43 \\
(1.4-5.78)\end{array}$} \\
\hline \multirow[t]{2}{*}{ No } & $113(83.7 \%)$ & $125(92.6 \%)$ & $238(88.1 \%)$ & & \\
\hline & $135(100 \%)$ & $135(100 \%)$ & $270(100 \%)$ & & \\
\hline
\end{tabular}

* Chi-squared test with Yates correction

Table 2. Association of urinary tract infection, low birth weight, an Apgar score less than 7 at 5 minutes and admission to the intensive care unit for newborns (Neo ICU).

\begin{tabular}{|c|c|c|c|c|c|}
\hline & \multicolumn{2}{|c|}{ Urinary Tract Infection } & & \multirow[t]{2}{*}{$p$} & \multirow{2}{*}{$\begin{array}{c}\text { OR (IC95\%) } \\
\text { (IC 95\%) }\end{array}$} \\
\hline & Present & Absent & & & \\
\hline \multicolumn{6}{|c|}{ Low Birth Weight } \\
\hline Yes & $29(21.5 \%)$ & $8(5.9 \%)$ & $37(13.7 \%)$ & \multirow{3}{*}{$* 0.009$} & \multirow{3}{*}{$\begin{array}{c}4.0 \\
(1.66-9.98)\end{array}$} \\
\hline \multirow[t]{2}{*}{ No } & $106(78.5 \%)$ & $127(94.1 \%)$ & $233(86.3 \%)$ & & \\
\hline & $135(100 \%)$ & $135(100 \%)$ & $270(100 \%)$ & & \\
\hline \multicolumn{6}{|c|}{ Apgar score $<7$ in $5 \mathrm{~min}$} \\
\hline Yes & $1(0.7 \%)$ & $2(1.5 \%)$ & $3(1.1 \%)$ & \multirow{3}{*}{$* 1.0$} & \multirow{3}{*}{$\begin{array}{c}0.5 \\
(0.02-7.07)\end{array}$} \\
\hline \multirow[t]{2}{*}{ No } & $134(99.3 \%)$ & $133(98.5 \%)$ & $267(98.9 \%)$ & & \\
\hline & $135(100 \%)$ & $135(100 \%)$ & $270(100 \%)$ & & \\
\hline \multicolumn{6}{|c|}{ ICU-Neo admission } \\
\hline Yes & $12(8.9 \%)$ & $10(7.4 \%)$ & $22(8.1 \%)$ & \multirow{3}{*}{$* 0.82$} & \multirow{3}{*}{$\begin{array}{c}1.22 \\
(0.47-3.18)\end{array}$} \\
\hline \multirow[t]{2}{*}{ No } & $123(91.1 \%)$ & $125(92.6 \%)$ & $248(91.9 \%)$ & & \\
\hline & $135(100 \%)$ & $135(100 \%)$ & $270(100 \%)$ & & \\
\hline
\end{tabular}

*Chi-squared test with Yates correction

\section{DISCUSSION}

The frequency of urinary tract infections during pregnancy is becoming more important because of various complications that may occur due to infection, including the premature rupture of membranes, preterm delivery, low birth weight and fetal death $(2,29,31)$. This study found that $15.6 \%$ of pregnant women suffer 
from a UTI. This value is higher than that found by other studies, suggesting that the frequency of UTIs in pregnant women ranges from 2.0 to $10 \%(8,20,26)$.

Asymptomatic bacteriuria $(\mathrm{AB})$ was reported in $5.2 \%$ of the pregnant women in this study. Similar information was found in another study with 290 pregnant women, with an $\mathrm{AB}$ rate of $6.2 \%$ (16). Pregnant women presenting with $\mathrm{AB}$ are exposed to a 20-30 fold greater risk of developing pyelonephritis (9). The treatment of asymptomatic bacteriuria resulting in pyelonephritis is a rare occurrence during pregnancy, indicating the importance of prenatal screening (12). Previous studies have demonstrated an incidence of pyelonephritis ranging from 1.3 to $1.4 \%$ in pregnant women $(14,28)$, whereas in this study, the frequency of pyelonephritis in pregnant women was $1.2 \%$.

Urine culture is considered to be the gold standard for diagnosing a UTI, allowing for the identification of the etiologic agent and quantification of bacteria in the urine. Thus, it is essential to perform this examination during prenatal screening, because it allows for early treatment and helps to prevent future consequences for both the mother and neonate $(5,19)$. The distribution of microorganisms found in this study is consistent with data from previous authors, who also identified $E$. coli as the most frequent uropathogen, followed by other enterobacteria $(2,3,6,12,17,23,24,31)$. The $E$. coli isolated in the urine of the pregnant women in this study had high rates of resistance to ampicillin (42.5\%) and trimethoprim-sulfamethoxazole (31.9\%), consistent with that found by other authors $(3,9)$. The low cost of treatment and ease of access to the population encourages the empirical use of antimicrobials, which may cause the selection of more resistant bacteria, complicating the therapy $(8,12,22)$. The prescription of antibiotics should be restricted to cases with a sensitivity shown in the antibiogram $(12,23)$. Regarding antimicrobial susceptibility, E. coli showed sensitivity to norfloxacin (91.4\%), nitrofurantoin (80.8\%) and ceftriaxone (74.4\%). A study of 874 pregnant patients in Mexico City identified reduced rates of sensitivity to ampicillin (27\%) and trimethoprim-sulfamethoxazole (40\%); however, the highest sensitivity was to nitrofurantoin (79\%) (13). The high level of sensitivity to nitrofurantoin (displayed in vitro) allowed for it to be considered a suitable treatment for urinary infections during pregnancy among the sample studied (3).

Although most of the bacteria isolated were found to have great sensitivity to norfloxacin and ciprofloxacin, these drugs should not be used as a first-line treatment for UTIs in pregnant women due to limited scientific information in this group of patients. The use of these drugs has been indicated in only specific cases, for example, in cases of severe pyelonephritis and bacterial multidrug resistance (8, $18,31)$. It is important to mention the presence of $S$. agalactiae in $5.2 \%(7 / 135)$ of the positive urine cultures in this study because vaginal and urinary tract colonization by this pathogen is an important risk factor for perinatal infection and complications, such as the premature rupture of membranes, chorioamnionitis, preterm delivery and neonatal sepsis $(1,4,30)$. 
Among the perinatal aspects evaluated in the present study, preterm delivery was present in $16.3 \%$ of the pregnant women with UTIs, with a significant association between these variables. A similar study that aimed to assess the association of obstetric outcomes and the presence of UTIs during pregnancy found a rate of preterm births of $12.4 \%$ in women with UTIs (2). However, another study that aimed to verify risk factors in pregnant women with UTIs identified a rate of preterm births of $7.44 \%$, and $13.82 \%$ of the newborns had a low birth weight, with no statistically significant association with UTIs (28).

A retrospective study of pregnant women that assessed the association of preterm labour and urinary tract infection showed a significant association of 78.3\% for preterm newborn infants delivered from women with UTIs, and these babies were also admitted to the Neo ICU, whereas in the control group, only $5.4 \%$ had perinatal complications associated with preterm births (19). The likely mechanism that triggers preterm delivery is related to the production of phospholipase A2 and subsequent prostaglandin activation (27).

The premature rupture of fetal membranes has a multifactorial etiology, and among other related factors, exogenous UTIs were significantly associated with this condition (15). However, the lack of this association in the present sample can be attributed to information missing from the medical records of patients studied.

In this series, there was no association between having a UTI and an Apgar score less than 7 at 5 minutes, and the newborns showed good perinatal conditions and did not need to be admitted to the Neo ICU. A similar study conducted recently showed no statistically significant difference in having an Apgar score less than 7 at 5 minutes between women with and without urinary infections (21).

In a recent meta-analysis comparing the use of prophylaxis and treatment in women with UTIs, it was observed that pregnant women with asymptomatic bacteriuria who used antibiotics decreased their chances of progressing to pyelonephritis by $77 \%$ when compared to those treated with a placebo $(p<0.0001$, RR 0.23 , CI95\% $=0.13$ to 0.41 ). A reduction in birth weight was also observed in newborns weighing less than $2.500 \mathrm{~g}$ from pregnant women who used antibiotics $(p=0.006$, RR $0.66, C 195 \%=0.49$ to 0.89$)(20)$. The treatment of pregnant women with asymptomatic bacteriuria may improve perinatal outcome (31).

\section{CONCLUSION}

The frequency of UTIs in pregnant women was $15.6 \%$, and E. coli was found to be the most frequent uropathogen. These particular strains demonstrated a high rate of resistance to ampicillin and trimethoprim-sulfamethoxazole. Urinary tract infection during pregnancy had a significant association with preterm delivery and low birth weight in newborns. Despite the perinatal adverse outcomes that were described, the follow-up prenatal care and early detection and treatment of urinary tract infection in pregnant women allowed for better conditions for 
newborns and improved Apgar scores. These data reinforce the requirement for the routine request of urine culture in the treatment of urinary tract infection during prenatal care, thereby contributing to the reduction of the perinatal complications associated with infection.

\section{REFERENCES}

1. Anderson BL, Simhan HN, Simons KM, Wiesenfeld HC. Untreated asymptomatic group B streptococcal bacteriuria early in pregnancy and chorioamnionitis at delivery. Am J Obstet Gynecol 196: 524 e521-525, 2007.

2. Archabald KL, Friedman A, Raker CA, Anderson BL. Impact of trimester on morbidity of acute pyelonephritis in pregnancy. Am J Obstet Gynecol 201: 406 e401-404, 2009.

3. Bean DC, Krahe D, Wareham DW. Antimicrobial resistance in community and nosocomial Escherichia coli urinary tract isolates, London 2005-2006. Ann Clin Microbiol Antimicrob 7: 1-14, 2008.

4. Borger IL, d'Oliveira REC, Castro ACD, Mondino SSB. Streptococcus agalactiae in pregnant women: prevalence of colonization and antimicrobial susceptibility evaluation. Rev Bras Ginecol Obstet 27: 575-579, 2005.

5. Correa LA, Canalini AF, Matheus WE. Etiologia das infecções do trato urinário. Int Braz J Urol 29: 7-10, 2003.

6. Correia C, Costa E, Peres A, Alves M, Pombo G, Estevinho L. [Etiology of urinary tract infections and antimicrobial susceptibility of urinary pathogens]. Acta Med Port 20: 543-550, 2007.

7. Duarte G, Marcolin AC, Quintana SM, Cavalli RC. [Urinary tract infection in pregnancy]. Rev Bras Ginecol Obstet 30: 93-100, 2008.

8. Duarte G, Marcolin AC, Gonçalves CV, Quintana SM, Berezowski AT, Nogueira AA, Cunha SP. Urinary infection in pregnancy: analysis of diagnostic methods and treatment. Rev Bras Ginecol Obstet 24: 471-477, 2002.

9. Enayat K, Fariba F, Bahram N. Asymptomatic bacteriuria among pregnant women referred to outpatient clinics in Sanandaj, Iran. Int Braz J Urol 34: 699-704, 2008.

10. Graninger W. Pivmecillinam--therapy of choice for lower urinary tract infection. Int J Antimicrob Agents 22: 73-78, 2003.

11. Gunes G, Gunes A, Tekiner S, Karaoglu L, Kaya M, Pehlivan E. Bacteriuria and socioeconomic associations among pregnant women in Malatya, Turkey. Public Health 11: 1039-1041, 2005.

12. Guneysel O, Onur O, Erdede M, Denizbasi A. Trimethoprim/sulfamethoxazole resistance in urinary tract infections. J Emerg Med 36: 338-341, 2009.

13. Hernández-Blas F, Carmona JML, Moctezuma JRR, Pedrero MLP, Gutierrez RSR, Aguirre ARO. [Asymptomatic bacteruiria frequency in pregnant women and uropathogen in vitro antimicrobial sensitivity]. Ginecol Obstet Mex 75: 325-331, 2007.

14. Hill JB, Sheffield JS, McIntire DD, Wendel-Jr GD. Acute pyelonephritis in pregnancy. Obstet Gynecol 105: 18-23, 2005.

15. Karat C, Madhivanan P, Krupp K, Poornima S, Jayanthi NV, Suguna JS, Mathai E. The clinical and microbiological correlates of premature rupture of membranes. Indian J Med Microbiol 24: 283-285, 2006.

16. Khattak AM, Khattak S, Khan H, Ashiq B, Mohammad D, Rafiq M. Prevalence of asyntomatic bacteriuria in pregnant women.Pakistan. J Med Sci 22: 162-166, 2006.

17. Koch CR, Ribeiro JC, Schnor OH, Zimmermann BS, Muller FM, D'Agostin J, Machado V, Zhang L. [Antimicrobial resistance of uropathogens among outpatients, 2000-2004]. Rev Soc Bras Med Trop 41: 277-281, 2008.

18. Krcmery S, Hromec J, Demesova D. Treatment of lower urinary tract infection in pregnancy. Int $J$ Antimicrob Agents 17: 279-282, 2001. 
19. Lucio-González LR, Escudero A, Rodríguez-Vega E, Vázquez-Caamaño MP, Vaquerizo O, Herrera FJ. Asociación entre las infecciones del tracto urinario y el parto pretérmino. Progr Obstet Ginecol 48: 373-378, 2005.

20. Masson P, Matheson S, Webster AC, Craig JC. Meta-analyses in prevention and treatment of urinary tract infections. Infect Dis Clin North Am 23: 355-385, 2009.

21. Mazor-Dray E, Levy A, Schlaeffer F, Sheiner E. Maternal urinary tract infection: is it independently associated with adverse pregnancy outcome? J Matern Fetal Neonatal Med 22: 124-128, 2009.

22. Nys S, van Merode T, Bartelds AI, Stobberingh EE. Urinary tract infections in general practice patients: diagnostic tests versus bacteriological culture. J Antimicrob Chemother 57: 955-958, 2006.

23. Pires MC, Frota KS, Martins Jr PO, Correia AF, Cortez-Escalante JJ, Silveira CA. [Prevalence and bacterial susceptibility of community acquired urinary tract infection in University Hospital of Brasilia, 2001 to 2005]. Rev Soc Bras Med Trop 40: 643-647, 2007.

24. Poletto KQ, Reis C. [Antimicrobial susceptibility of the uropathogens in out patients in Goiania City, Goias State]. Rev Soc Bras Med Trop 38: 416-420, 2005.

25. Santos JF, Ribeiro RM, Rossi P, Haddad JM, Guidi HG, Pacetta AM, Pinotti JA. Urinary tract infections in pregnant women. Int Urogynecol J Pelvic Floor Dysfunct 13: 204-209, 2002.

26. Schieve LA, Handler A, Hershow R, Persky V, Davis F. Urinary tract infection during pregnancy: its association with maternal morbidity and perinatal outcome. Am J Public Health 84: 405-410, 1994.

27. Schnarr J, Smaill F. Asymptomatic bacteriuria and symptomatic urinary tract infections in pregnancy. Eur J Clin Invest 38: 50-57, 2008.

28. Sharma P, Thapa L. Acute pyelonephritis in pregnancy: a retrospective study. Aust N Z J Obstet Gynaecol 4: 313-315, 2007.

29. Sheffield JS, Cunningham FG. Urinary tract infection in women. Obstet Gynecol 106: 1085-1092, 2005.

30. Smaill F. Asymptomatic bacteriuria in pregnancy. Best Pract Res Clin Obstet Gynaecol 21: 439-450, 2007.

31. Turiño-Luque JD, Fraile MR. Etiología y sensibilidad antimicrobiana en las infecciones urinarias bajas de la embarazada en España. Prog Obstet Ginecol 49: 238-246, 2006.

32. Wing DA, Rumney PJ, Preslicka CW, Chung JH. Daily cranberry juice for the prevention of asymptomatic bacteriuria in pregnancy: a randomized, controlled pilot study. J Urol 180: 1367-1372, 2008. 